\title{
Molecular prevalence of intestinal parasites infections in children with diarrhea in Franceville, Southeast of Gabon
}

Sandrine Lydie Oyegue-Liabagui ${ }^{1,2^{*}}$ (D), Nal Kennedy Ndjangangoye ${ }^{1,2}$, Lady Charlene Kouna ${ }^{2}$, Gwladys Mirlande Lekolo², Franck Mounioko ${ }^{3}$, Sylvie Kwedi Nolna ${ }^{4}$ and Jean Bernard Lekana-Douki ${ }^{2,5}$

\begin{abstract}
Background: Pediatric diarrhea caused by a range of pathogens, including intestinal parasites, is one of main causes of death among children under 5 years of age. The distribution of these parasitic infections overlaps in many environmental, socioeconomic and epidemiological settings. Their distribution and prevalence varies from region to region. In the current study, we assess the prevalence of intestinal parasites among pediatric patients with syndromic diarrheal disease living in Franceville, Gabon.

Methods: A cross-sectional study conducted in the Amissa Bongo Regional Hospital and Chinese-Gabonese Friendship Hospital in Franceville, between November 2016 and August 2017, enrolled a total of 100 diarrheic children between 0 and 180 months of age. Parasite detection in stool samples was performed using molecular diagnostic by PCR. Difference in means were tested by Student's t test and ANOVA while principal component analysis was used to determine the correlation between parasite distributions and age groups.

Results: The overall prevalence of intestinal parasite infection was 61\% (61/100). Hymenolepis sp and Cryptosporidium hominis/parvum were the most common parasites (31 and 19\%, respectively), followed by Encephalitozoon intestinalis (15\%), Trichuris trichiura (4\%), Dientamoeba fragilis (4\%), and Enterocytozoon bieneusi (2\%). The polyparasitism rate was $19.7 \%$, with $83.3 \%$ double and $16.7 \%$ triple infections. Protozoan infections (66.7\%) were more prevalent than helminths infections (33.3\%). Seasonal association of the circulation of intestinal parasite was statistically significant $(p=0.03)$. Correlations between different parasites was also observed.

Conclusion: The prevalence of intestinal parasitic infections is highest in diarrheic pediatric children. The prevalence of parasitic infections indicates that protozoa and helminths are the most common parasites in the Franceville environment. This study reinforces the importance of routine examination of diarrheic stool samples for the diagnostic of intestinal parasites. Further analyses are required to better understand the local epidemiology and risk factors associated with the transmission of intestinal parasites in Franceville, Gabon.
\end{abstract}

Keyswords: diarrhea, children, intestinal parasitic infections, molecular diagnostic, Franceville, Gabon.

\footnotetext{
*Correspondence: lyds_ass@yahoo.fr

'Ecole Doctorale Régionale d'Afrique Centrale en Infectiologie Tropicale (ECODRAC), Université des Sciences et Techniques de Masuku, BP 876 Franceville, Gabon

2Unité d'Evolution, Epidémiologie et Résistance Parasitaire (UNEEREP), Centre International de Recherches Médicales de Franceville (CIRMF), BP 769 Franceville, Gabon

Full list of author information is available at the end of the article
}

(c) The Author(s). 2020 Open Access This article is licensed under a Creative Commons Attribution 4.0 International License, which permits use, sharing, adaptation, distribution and reproduction in any medium or format, as long as you give appropriate credit to the original author(s) and the source, provide a link to the Creative Commons licence, and indicate if changes were made. The images or other third party material in this article are included in the article's Creative Commons licence, unless indicated otherwise in a credit line to the material. If material is not included in the article's Creative Commons licence and your intended use is not permitted by statutory regulation or exceeds the permitted use, you will need to obtain permission directly from the copyright holder. To view a copy of this licence, visit http://creativecommons.org/licenses/by/4.0/ The Creative Commons Public Domain Dedication waiver (http://creativecommons.org/publicdomain/zero/1.0/) applies to the data made available in this article, unless otherwise stated in a credit line to the data. 


\section{Background}

The World Health Organization (WHO) and United Nations International Children Emergency Fund define diarrhea as more than three loose or watery stools during a $24 \mathrm{~h}$ period. A duration of 14 days is the proposed criterion for acute diarrhea or persistent diarrhea [1]. According to the WHO, diarrheal disease is the world's second leading cause of pediatric deaths, killing around 525,000 children under 5 years old annually. Globally, there are approximately 1.7 billion cases of childhood diarrheal disease every year and diarrhea due to infection is widespread throughout the developing world $[2,3]$. In low-income countries, many of the risk factors for contracting diarrheal illnesses are linked to poor socioeconomic conditions, such as lack of access to safe water and sanitation, poor hygiene practices and unsafe human waste disposal $[4,5]$. Diarrhea can be related to a wide range of bacteria, viruses, and intestinal parasites [6].

Intestinal parasitic infections (IPIs), such as soiltransmitted helminths (STHs) and parasitic intestinal protozoa, have been described as the major worldwide causes of illnesses and disease in tropical and subtropical regions in the world [3, 7]. Besides causing mortality and morbidity, IPIs have been associated with impairment of physical and intellectual development as well as worsening of nutritional status during infancy [6, $8,9]$. Indeed, they cause undernutrition, abdominal pain, diarrhea, intestinal obstruction, anemia, ulcers and other health problems that can lead to delayed cognitive development and impaired learning [10].

STHs are among the most common infections worldwide. More than 1.5 billion people, or $24 \%$ of the world's population, are infected with soil-transmitted helminth infections worldwide. In areas where these parasites are intensively transmitted, over 267 million preschool-age children and over 568 million school-age children are infected [11]. Globally, 438.9 million people were infected with hookworm while 819 million were infected with Ascaris lumbricoides, and 464.6 million with Trichuris trichiura, with a large proportion occurring in Asia [3].

Intestinal protozoa that are most commonly associated with diarrhea in children include Entamoeba histolytica, Giardia lamblia/duodenalis, Blastocystis sp, Cryptosporidium sp, and Dientamoeba fragilis [12]. Globally, Cryptosporidium $s p$ has been identified as the most common diarrhea-causing protozoan [13] and giardiasis is experienced by approximately $33 \%$ of people in developing countries [14, 15]. Like Cryptosporidium $s p$ and Giardia, intestinal protozoa Blastocystis $s p$ and D. fragilis are both relevant due to their significant public health and socioeconomic implications. Indeed, D. fragilis is frequently detected in co-infection with multiple protozoans, especially Blastocystis $s p$ [16].
Depending on environmental, socioeconomic and geographical factors, the distribution and prevalence of IPIs varies from region to region. Gabon is a sub-Saharan African country with a high prevalence of intestinal infections $[17,18]$. In a number of studies conducted in Gabon, the burden of IPIs was found to be high in urban and rural areas. Nationwide, the prevalence of IPIs was found to be $61.1 \%$, including intestinal protozoa $(56.7 \%)$ and soil-transmitted infections (22.2\%). Factors such as inadequate water supplies, lack of proper health education and unsuitable sanitation favor the transmission and wide distribution of IPIs [19]. The distribution of intestinal parasites has been reported in some regions of Gabon, but few studies have assessed the prevalence of these parasites in pediatric diarrhea patients. A study conducted in Franceville on the etiology of diarrhea in children under 5 years old showed that viruses were the main agents responsible for diarrhea in children with an overall prevalence of $60.9 \%$ [20]. Another study conducted in Libreville, the capital of Gabon, showed that bacteria were responsible for acute diarrhea with a prevalence of $13 \%$ [21]. However, data on the involvement of IPIs in the etiology of infantile diarrhea in Franceville are not available. Conventional diagnostic of these intestinal parasites relies widely on microscopic examination of stool samples. However, coproscopic identification is limited by low sensitivity as evidenced in studies reporting a marked difference in the prevalence of intestinal parasites when comparing the results of coproscopic and molecular analyses [22]. The main objective of this study was to assess the prevalence of eighteen IPIs by microscopic and molecular diagnosis and their distribution according to age and seasonality, in children with diarrhea living in Franceville, south-east of Gabon.

\section{Methods \\ Study area and participants}

This study was conducted at the Amissa Bongo Regional Hospital and Chinese-Gabonese Friendship Hospital in Franceville, the capital of the Haut-Ogooue Province, Gabon. Children aged from 0 to 180 months old presenting a diarrhea syndrome with at least three bowel movements over $24 \mathrm{~h}$ were enrolled. Samples were collected between November 2016 and August 2017 in the pediatric wards of both hospitals and two samples, among which one blood sample and one stool sample, were collected per child. Over the weekend, stool samples were collected from children in the emergency ward. Samples were collected at home for children who were not admitted and left the hospital. After the inclusion of a patient, a clinical examination was conducted which was comprised of an interrogation, search of general signs, anthropometric parameters, and signs of 
dehydration. An examination of the digestive system was also performed. A brief clinical examination of the cardiopulmonary and neurological apparatus was also carried out.

\section{Sample collection}

A total of two types of samples (whole blood and stool) were collected from the 100 children included. Blood (2 $\mathrm{mL}$ ) was collected and distributed in EDTA tubes for a blood count test and in heparin tubes for urea, creatinine and ionogramm tests. When possible, stool samples were collected in sterile containers from diarrheal pediatric patients. Otherwise, a sterile container was given to the parents to collect the stool sample at home. These samples were analyzed by a direct examination followed by molecular analyzes. DNA was extracted using the QIAamp DNA Stool Mini kit (Qiagen, Hilden, Germany) according to the manufacturer's instructions.

\section{Direct examination}

Macroscopic examination was performed on each stool sample to note the appearance, consistency, color and possible presence of blood, mucus and adult forms of parasites. Direct microscopic examination after staining was carried out using the Kop-Color kit, according to the manufacturer's instructions (Para-Selles/Kop-Color II Fumouze . Fumouze Diagnostics; Levallois-Perret, France). The Kop-Color II kit is a differential staining process of parasitic elements using a mixture of staining agents one of which is Lugol. Briefly, after homogenizing the stool, a volume of stool equivalent to the size of a pea was placed in a hemolysis tube containing $1 \mathrm{~mL}$ of diluent (physiological water). The mixture is triturated and stirred to obtain a homogeneous suspension. $10 \mu \mathrm{L}$ of KOP-COLOR II were placed on a slide and 1 drop or $25 \mu \mathrm{L}$ of the stools suspension was added. The mixture thus obtained was well mixed. A coverglass was placed over the stool suspension and then examined using a microscope with white light (blue filter). Parasitic elements appear in yellow, yellow-orange or brownishyellow on a more or less dark blue background.

\section{PCR detection}

Eighteen [18] parasites, Cryptosporidium hominis/parvum, Cystoisospora belli, Entamoeba hartmani, Entamoeba histolytica/dispar, Dientamoeba fragilis, Trichomonas intestinalis, Blastocystis hominis Enterocytozoon bieneusi, Encephalitozoon intestinalis, Ancylostoma duodenale, Necator americanus, Ascaris lumbricoïdes, Enterobius vermicularis, Strongylö̈des stercoralis, Trichuris trichiura, Schistosoma mansoni, intercalatum, haematobium, Hymenolepis sp, were investigated using t sets of primers listed in Table 1. The identification of parasitic species was carried out using conventional PCR or multiplex amplification. Briefly, five microliters of DNA were amplified with a $1 \mathrm{X}$ Taq polymerase buffer (Invitrogen. Alphalab; Saint Laurent d'Aigouze, France), $0.8 \mu \mathrm{M}$ of each primer, $0.2 \mathrm{mM}$ dNTP (Invitrogen. Alphalab; Saint Laurent d'Aigouze, France), $1.5 \mathrm{mM} \mathrm{MgCl} 2$ and $0.024 \mathrm{U}$ of Taq DNA polymerase (Invitrogen. Alphalab; Saint Laurent d'Aigouze, France), for Cryptosporidium hominis/parvum, Cystoisospora belli, Entamoeba hartmani, Entamoeba histolytica/dispar, Dientamoeba fragilis, Trichomonas intestinalis, Blastocystis hominis Enterocytozoon bieneusi, Encephalitozoon intestinalis, Ancylostoma duodenale, Necator americanus, Enterobius vermicularis, Strongyloides stercoralis, Trichuris trichiura, Schistosoma mansoni, intercalatum, haematobium, Hymenolepis sp. For Ascaris lumbricoïdes, five microliters of DNA were amplified with a $1 \mathrm{X}$ Taq polymerase buffer, $0.2 \mu \mathrm{M}$ of each primer, $0.2 \mathrm{mM}$ dNTP, 1.5 $\mathrm{mM} \mathrm{MgCl} 2$ and $0.024 \mathrm{U}$ of Taq DNA polymerase. Specific cycling programs for each species are described in the corresponding references mentioned in Table 1 . PCR products were detected by $2 \%$ agarose gel electrophoresis stained with GelRed $^{\circ}$ (Interchim; Montluçon, France).

\section{Statistical analysis}

The data collected were entered into an Excel spreadsheet and analyzed using the software package IBM SPSS Statistics version 21.0 (SPSS inc., Chicago, USA) and R software version 3.5.3. The Pearson Chi square for categorical variables, Student's $t$ test and ANOVA for the comparison of group means, were used. To compare multiple groups of data, the non-parametric Kruskal-Wallis test was used. The Mann-Whitney U non-parametric test was used for pairwise comparisons. Possible correlations between parasite distributions and age groups were identified using principal component analysis (PCA). The statistical significance was set at $p<0.05$.

\section{Results \\ Study population}

A total of 100 diarrheal pediatric children aged from 2 to 169 months were included in the study. The sex ratio was 1.5 (60 males and 40 females). The mean and median age of children included were 24.8 and 14.5 months old, respectively. Diarrheal syndrome was predominantly found in children aged less than 48 months old $(p<$ $0.005)$. The children's demographical and clinical characteristics are summarized in Table 2 . The mean age of the infected and uninfected children was $28.3 \pm 4.3$ and $19.4 \pm 3.4$ months old, respectively (no statistically significant difference). The differences were not statistically significant for body temperature and weight between infected $\left(37.9 \pm 0.2^{\circ} \mathrm{C}\right.$ and $\left.11.9 \pm 0.9 \mathrm{Kg} ; p=0.5\right)$ and uninfected $\left(38.2 \pm 0.2^{\circ} \mathrm{C}\right.$ and $\left.10.1 \pm 1.05 \mathrm{Kg} ; p=0.3\right)$ children. Haemoglobin, red blood cell, white blood cell and 
Table 1 Sequences of primers sets used and targeted genes

\begin{tabular}{|c|c|c|c|c|}
\hline Intestinal parasite & Names & Primers $\left(5^{\prime} \rightarrow 3^{\prime}\right)$ & Target region & Reference \\
\hline \multicolumn{5}{|l|}{ Protozoa } \\
\hline \multirow{2}{*}{$\begin{array}{l}\text { Cryptosporidium parvum/ } \\
\text { hominis }\end{array}$} & 1PSF & AAC TIT AGC TCC AGT TGA GAA AGT ACT C & hsp70 gene & (Garces-Sanchez, Wilderer et al. 2009) \\
\hline & 1PSR & CAT GGC TCT TTA CCG TTA AAG AAT TCC & & \\
\hline \multirow[t]{2}{*}{ Blastocystis hominis } & $\mathrm{BH} 1$ & GCT TAT CTG GTT GAT CCT GCC AGT & 16 like RNA & (Init, Foead et al. 2007) \\
\hline & $\mathrm{BH} 2$ & TGA TCC TTC CGC AGG TTC ACC TAC A & & \\
\hline \multirow[t]{2}{*}{ Cystoisospora belli } & Ib213F & GGA TAT TCC CTG CAG CAT GT & $5,8 \mathrm{~S}$ rRNA/ITS2 & (Taniuchi, Verweij et al. 2011) \\
\hline & Ib213R & CGG GAC ACA ACT CAA CAC TG & & \\
\hline \multirow[t]{2}{*}{ Encephalitozoon intestinalis } & Eint214F & CAC CAG GTT GAT TCT GCC TGA C & SSU rRNA & (Verweij, Ten Hove et al. 2007) \\
\hline & Eint214R & CTA GTT AGG CCA TTA CCC TAA CTA CCA & & \\
\hline \multirow[t]{2}{*}{ Enterocytozoon bieneusi } & EblTS-89F & TGT GTA GGC GTG AGA GTG TAT CTG & SSU rRNA & (Verweij, Ten Hove et al. 2007) \\
\hline & EblTS-191R & CAT CCA ACC ATC ACG TAC CAA TC & & \\
\hline \multirow[t]{2}{*}{ Dientamoeba fragilis } & DFpn_1f & GCC AAG GAA GCA CAC TAT GG & SSU rRNA & (Roser, Nejsum et al. 2013) \\
\hline & DFpn_364r & GTA AGT TTC GCG CCT GCT & & \\
\hline \multirow[t]{2}{*}{ Trichomonas intestinalis } & $\mathrm{TH} 3$ & TGT AAA CGA TGC CGA CAG AG & SSU rRNA & (Crucitti, Abdellati et al. 2004) \\
\hline & TH5 & CAA CAC TGA AGC CAA TGC GAG C & & \\
\hline \multirow[t]{2}{*}{ Entamoeba histolytica } & EnthF & ATG GCC AAT TCA TTC AAT GA & SSU rRNA & (Suzuki, Kobayashi et al. 2008) \\
\hline & EnthR & TAC TTA CAT AAA GTC TTC AAA ATG T & & \\
\hline \multirow[t]{2}{*}{ Entamoeba dispar } & EntdF & GTT AGT TAT CTA ATT TCG ATT AGA AC & SSU rRNA & (Suzuki, Kobayashi et al. 2008) \\
\hline & EntdR & ACA CCA CTT ACT ATC CCT ACC TA & & \\
\hline \multirow[t]{2}{*}{ Entamoeba hartmanni } & EhartF & GTG AAG AGA AAG GAT ATC CAA AGT & SSU rRNA & (Suzuki, Kobayashi et al. 2008) \\
\hline & EhartR & ATA TCA TIT TCA ACT ACG AGC & & \\
\hline \multicolumn{5}{|l|}{ Helminths } \\
\hline \multirow[t]{2}{*}{ Ascaris lumbricoides } & Alum96F & GTA ATA GCA GTC GGC GGT TTC Tा & ITS1 & (Wiria, Prasetyani et al. 2010) \\
\hline & Alum183R & GCC CAA CAT GCC ACC TAT TC & & \\
\hline \multirow[t]{2}{*}{ Enterobius vermicularis } & EVpn_1f & CAA CAC TTG CAC GTC TCT TCA & 5S rRNA & (Roser, Nejsum et al. 2013) \\
\hline & EVpn_195r & ATT GCT CGT TTG CCG ATT AT & & \\
\hline \multirow[t]{2}{*}{ Trichuris trichiura } & TtF & TTG AAA CGA CTT GCT CAT CAA CTT & $18 \mathrm{~S}$ & (Liu, Gratz et al. 2013) \\
\hline & TtR & CTG ATT CTC CGT TAA CCG TTG TC & & \\
\hline \multirow[t]{2}{*}{ Strongyloides stercoralis } & Stro-1530F & GAA TTC CAA GTA AAC GTA AGT CAT TAG C & $18 \mathrm{~S}$ & (Verweij, Canales et al. 2009) \\
\hline & Stro-1630R & TGC CTC TGG ATA TTG CTC AGT TC & & \\
\hline \multirow[t]{2}{*}{ Ancylostoma duodenalis } & Ad125F & GAA TGA CAG CAA ACT CGT TGT TG & ITS2 & (Verweij, Brienen et al. 2007) \\
\hline & Ad195R & ATA CTA GCC ACT GCC GAA ACG T & & \\
\hline \multirow[t]{2}{*}{ Necator americanus } & $\mathrm{Na58F}$ & CTG TIT GTC GAA CGG TAC TTG C & ITS2 & (Verweij, Brienen et al. 2007) \\
\hline & $\mathrm{Na158R}$ & ATA ACA GCG TGC ACA TGT TGC & & \\
\hline \multirow[t]{2}{*}{ Schistosoma mansoni } & Smcyt748F & CCC TGC CAA ATG AAG AGA AAA C & Mitochondrial DNA & (ten Hove, Verweij et al. 2008) \\
\hline & Smcyt847R & TGG GTG TGG AAT TGG TTG AAC & & \\
\hline \multirow[t]{2}{*}{ Schistosoma intercalatum } & Sh110 & TTC CTC CAA CTA CCA TCT TAT CTC & Sh110 & (Abbasi, King et al. 2007) \\
\hline & Sm-SL & AAC CGT CAC GGT TाT ACT CTT GTG & & \\
\hline \multirow[t]{2}{*}{ Hymenolepsis sp. } & Pr-a & TGG TाT TाT GTG CAT CCT GAG GTT TA & $\mathrm{COI}$ & (Muehlenbachs, Bhatnagar et al. 2015) \\
\hline & Pr-b & AGA AAG AAC GTA ATG AAA ATG AGC AAC & & \\
\hline
\end{tabular}

platelet values showed no significant difference between the two groups of children. Infected children had a significantly higher creatinine level $(47.7 \pm 3.8 \mathrm{mmol} / \mathrm{L})$ than uninfected children $(25.3 \pm 2.7 \mathrm{mmol} / \mathrm{L} ; p=0.02)$.
Clinical examination revealed that the most frequent signs associated with diarrhea were fever $(60 \% ; n=60 / 100)$, vomiting ( $47 \% ; n=47 / 100)$, dehydration $(17 \% ; n=17 / 100)$, weight-loss delay $(16 \% ; n=16 / 100)$ and abdominal pain 
Table 2 Demographical and hematological parameters of the patients (mean \pm SD)

\begin{tabular}{|c|c|c|c|}
\hline & \multicolumn{3}{|c|}{ Franceville children } \\
\hline & Infected $(n=61)$ & Uninfected $(n=39)$ & $\mathrm{p}$ \\
\hline Age (months) & $28.3 \pm 4.3$ & $19.4 \pm 3.4$ & 0.06 \\
\hline Temperature & $37.9 \pm 0.2$ & $38.2 \pm 0.2$ & 0.5 \\
\hline Weight (Kg) & $11.9 \pm 0.9$ & $10.1 \pm 1.05$ & 0.3 \\
\hline Haemoglobin (g/dL) & $10.4 \pm 0.6$ & $11.7 \pm 0.5$ & 0.1 \\
\hline Red blood cells $\left(10^{6}\right.$ cells $\left./ \mathrm{mm}^{3}\right)$ & $4.3 \pm 0.7$ & $4.3 \pm 0.2$ & 0.7 \\
\hline White blood cells $\left(10^{3}\right.$ cells $\left./ \mathrm{mm}^{3}\right)$ & $13.2 \pm 2.1$ & $9.7 \pm 1.1$ & 0.1 \\
\hline Platelets $\left(10^{3}\right.$ cells $\left./ \mathrm{mm}^{3}\right)$ & $358.8 \pm 313.8$ & $361 \pm 467.2$ & 0.2 \\
\hline Creatinine (mmol/L) & $47.7 \pm 3.8$ & $25.3 \pm 2.7$ & 0.02 \\
\hline
\end{tabular}

leucocyte counts, hemoglobin concentrations and creatinine infected and uninfected children. Statistical significance was calculated using a student's $t$ test. $\mathrm{SD}=$ standard deviation

( $8 \% ; n=8 / 100)$. These signs were assessed according to the usual clinical criteria: weight-to-height and height-to-age ratio, vomiting and fever.

\section{Prevalence of intestinal parasites}

Microscopic examination of stool samples did not lead to the detection of parasites among the 81 participants examined. However, the PCR test revealed at least one intestinal parasite in 61 stools samples with $61 \%$ of global prevalence. There were six species of intestinal parasites among which four protozoans (Dientamoebla fragilis, Encephalitozoon intestinalis, Enterocytozoon bieneusi, Crytosporidium hominis/parvum and two helminths (Trichuris trichiura and Hymenolepis sp). Cryptosporidium hominis/parvum (19\%) was the most prevalent protozoa, followed by Encephalitozoon intestinalis (15\%). In helminths infections, the highest prevalence was observed with Hymenolepis sp (31\%), which represents the highest prevalence of parasitic infections detected among all the children included (Fig. 1).

Polyparasitism carrying two to three different species were detected in $19.7 \%(12 / 61)$ of infected children. Ten of the polyinfected children harbored two parasitic species $(83.3 \%)$ and two of them harbored three parasitic species $(16.7 \%)$. The most representative polyinfection was that of Encephalitozoon intestinalis and Hymenolepis sp with a prevalence of $41.7 \%$, followed by that of Cryptosporidium hominis/parvum and Hymenolepis sp (25\%). Polyinfections of Cryptosporidium hominis/parvum/Encephalitozoon intestinalis and Hymenolepis sp/Trichuris trichiura were detected in infected children with a prevalence of $16.7 \%$, while polyinfections were poorly represented with a prevalence of $8.3 \%$.

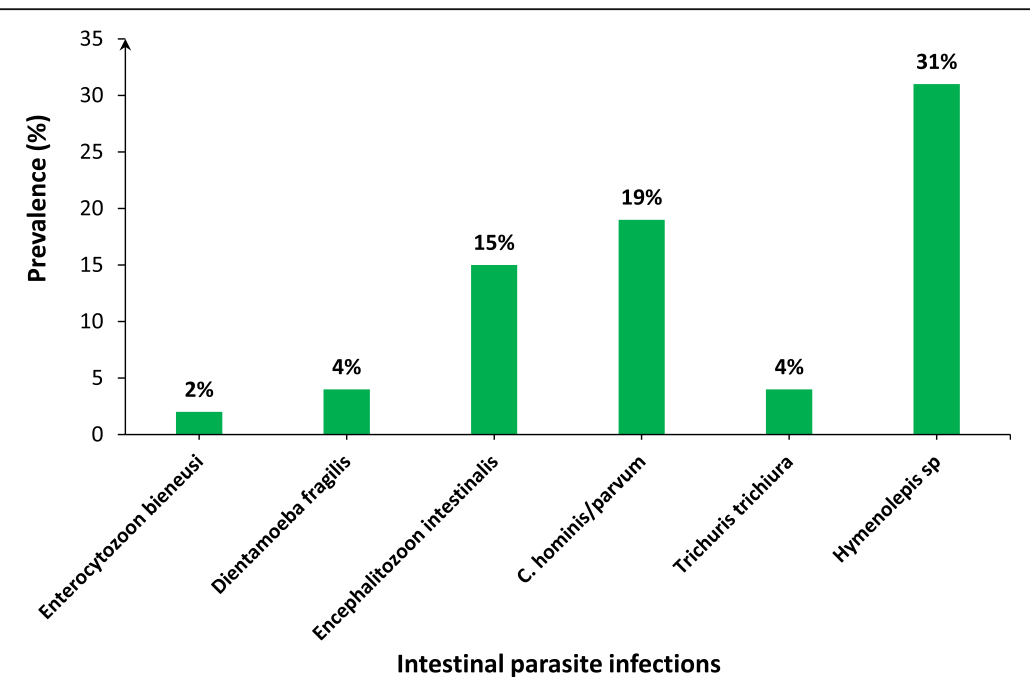

Fig. 1 Prevalence of intestinal parasite infections. Parasite infection in 100 stools from these children were assayed using PCR. The number of positive cases are indicated on the figure, each bar represents the prevalence of each parasite 


\section{Distribution of intestinal parasite infections by age and gender}

In order to assess the distribution of intestinal parasites according to age, the children were subdivided into seven age groups ranging from 2 to 169 months. The overall prevalence of intestinal parasites $(85.2 \% ; n=52 / 61)$ was found in children under 49 months of age. Children under 6 months of age were infected with 3 parasitic species which are Encephalitozoon intestinalis, Hymenolepis sp, and Trichuris trichiura. In the 6 to 24 months age group, five species were found (Dientamoebla fragilis, Encephalitozoon intestinalis, Cryptosporidium hominis/parvum, Trichuris trichiura and Hymenolepis sp). In the 25 to 48 months age group, Enterocytozoon bieneusi, Encephalitozoon intestinalis, Cryptosporidium hominis/parvum and Hymenolepis $s p$ were identified (Table 3). Otherwise, in the 49 to 72 months age group, only Hymenolepis $s p$ was detected. The 73 to 96 months, 97 to 120 months and the over 121 months age groups were infected with two different parasite species. The prevalence of intestinal parasites was statistically significant among the age groups $(p=0.03)$. The global prevalence of intestinal parasites was higher in the 6 to 24 months age group compared to the less than 6 months age group $(p=0.03)$. Similarly, a statistically significant difference in prevalence was also observed between the 6 to 24 months age group and the 49 to 72 months $(p=0.02), 73$ to 96 months $(\mathrm{p}=0.03)$, 97 to 120 months $(\mathrm{p}=0.03)$ and the over 120 months $(\mathrm{p}=$ $0.03)$ age groups.

The prevalence of intestinal parasites by gender among infected children was assessed. Although the difference in the prevalence of intestinal parasites was not statistically significant between males and females, boys had a higher prevalence (63.3\%) than girls 57.5\%). Among the six parasitic species detected, T. trichiura and Enterocytozoon bieneusi were present only in the male population. However, the other four remaining species were found in both male and female children (data not shown).

\section{Distribution of intestinal parasites species by season}

The prevalence of parasites was unevenly distributed from month to month over a 1 year period (Fig. 2). The highest prevalence of parasitic infections was observed during the short dry season (December to January) and the long dry season (May to September), (76.9\%: $n=10$ / 13 and 64.3\%: $n=18 / 28$, for the short dry season and the long dry season, respectively). Moreover, the lowest prevalence of parasitic infections was seen during the months of February to April (long rainy season) and in November (during the short rainy season), (58.5\%: $n=$ $31 / 53$ and $33.3 \%: n=2 / 6$, for the long rainy season and the month of November, respectively). The distribution of intestinal parasites was also analyzed monthly. The distribution of Hymenolepis sp was consistently found throughout the year except in July with the highest prevalence observed in February which corresponds to the long rainy season (35.5\%: $n=11 / 31)$. The same is true for Encephalitozoon intestinalis, Cryptosporidium hominis/parvum and Trichuris trichiura and Cryptosporidium hominis/parvum whose prevalence peaked during

Table 3 Distribution of intestinal parasites by age groups of children

\begin{tabular}{|c|c|c|c|c|c|c|c|c|}
\hline \multirow[t]{2}{*}{ Type of parasite } & $<6(n=4)$ & $6-24(n=40)$ & $25-48(n=8)$ & $49-72(n=3)$ & $73-96(n=2)$ & $97-120(n=2)$ & $\geq 121(n=2)$ & $\mathrm{N}^{\circ}(\%)$ \\
\hline & $\mathrm{N}^{\circ}(\%)$ & $\mathrm{N}^{\circ}(\%)$ & $\mathrm{N}^{\circ}(\%)$ & $\mathrm{N}^{\circ}(\%)$ & $\mathrm{N}^{\circ}(\%)$ & $\mathrm{N}^{\circ}(\%)$ & \multicolumn{2}{|l|}{$\mathrm{N}^{\circ}(\%)$} \\
\hline Enterocytozoon bieneusi & $0(0)$ & $0(0)$ & $0(0)$ & $0(0)$ & $0(0)$ & $0(0)$ & $1(50)$ & $1(1.6)$ \\
\hline Dientamoeba fragilis & $0(0)$ & $4(10)$ & $0(0)$ & $0(0)$ & $0(0)$ & $0(0)$ & $0(0)$ & $4(6.6)$ \\
\hline Encephalitozoon intestinalis & $1(25)$ & $6(15)$ & $1(12.5)$ & $0(0)$ & $0(0)$ & $0(0)$ & $0(0)$ & $8(13.1)$ \\
\hline Cryptosporidium hominis/parvum & $0(0)$ & $7(17.5)$ & $3(37.5)$ & $0(0)$ & $1(50)$ & $1(50)$ & $1(50)$ & $13(21.3)$ \\
\hline Hymenolepis sp & $2(50)$ & $15(37.5)$ & $1(12.5)$ & $3(100)$ & $1(50)$ & $0(0)$ & $0(0)$ & $22(36.1)$ \\
\hline Trichuris trichiura & $0(0)$ & $1(2.5)$ & $0(0)$ & $0(0)$ & $0(0)$ & $0(0)$ & $0(0)$ & $1(1.6)$ \\
\hline $\begin{array}{l}\text { Encephalitozoon intestinalis/ } \\
\text { Hymenolepis sp }\end{array}$ & $1(25)$ & $2(5)$ & $1(12.5)$ & $0(0)$ & $0(0)$ & $0(0)$ & $0(0)$ & $4(6.6)$ \\
\hline C. hominis/parvum/Hymenolepis $s p$ & $0(0)$ & $1(2.5)$ & $1(12.5)$ & $0(0)$ & $0(0)$ & $0(0)$ & $0(0)$ & $2(3.3)$ \\
\hline $\begin{array}{l}\text { C. hominis/parvum/Encephalitozoon } \\
\text { intestinalis }\end{array}$ & $0(0)$ & $2(5)$ & $0(0)$ & $0(0)$ & $0(0)$ & $0(0)$ & $0(0)$ & $2(3.3)$ \\
\hline Trichuris trichiura/Hymenolepis $s p$ & $0(0)$ & $1(2.5)$ & $0(0)$ & $0(0)$ & $0(0)$ & $0(0)$ & $0(0)$ & $1(1.6)$ \\
\hline $\begin{array}{l}\text { Trichuris trichiura/Cryptos. hominis/ } \\
\text { parvum }\end{array}$ & $0(0)$ & $0(0)$ & $0(0)$ & $0(0)$ & $0(0)$ & $1(50)$ & $0(0)$ & $1(1.6)$ \\
\hline $\begin{array}{l}\text { Encephalitozoon intestinalis/Trichurus } \\
\text { trichiura/Hymenolepis sp }\end{array}$ & $0(0)$ & $1(2.5)$ & $0(0)$ & $0(0)$ & $0(0)$ & $0(0)$ & $0(0)$ & $1(1.6)$ \\
\hline $\begin{array}{l}\text { C. hominis/parvum/Enterocytozoon } \\
\text { bieneusi/Hymenolepis sp }\end{array}$ & $0(0)$ & $0(0)$ & $1(12.5)$ & $0(0)$ & $0(0)$ & $0(0)$ & $0(0)$ & $1(1.6)$ \\
\hline
\end{tabular}




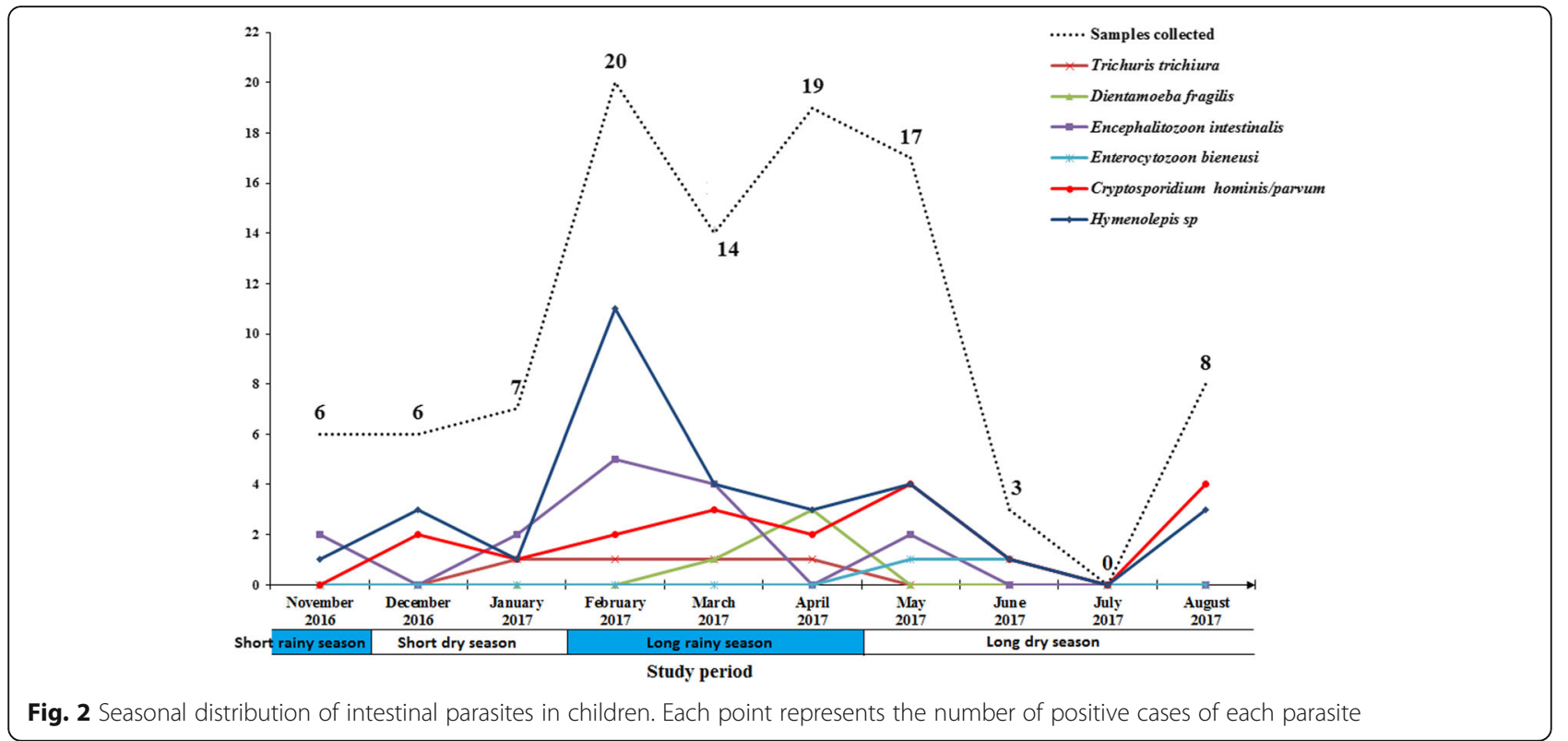

the long rainy season and the month of May (long dry season). For Dientamoeba fragilis, the highest prevalence was observed in April and Enterocytozoon bieneusi was found in May and June only. The distribution of parasite species by month was significantly different $(p=0.0003)$.

\section{Association between intestinal parasites and age groups}

The association between the different parasitic species and the distribution according to the different age groups was determined using the principal component analysis (PCA). The results of the correlation analysis showed that the main parasitic species including Cryptosporidium hominis/parvum, Encephalitozoon intestinalis, Hymenolepis sp, Dientamoeba fragilis and Trichuris trichiura were positively correlated with each other. Only Enterocytozoon bieneusi was negatively correlated with four other species including Encephalitozoon intestinalis, Hymenolepis sp. Dientamoeba fragilis and Trichuris trichiura $(\mathrm{r}=-0.4,-0.3$ and -0.1 , respectively). No correlation was found between Enterocytozoon bieneusi and Cryptosporidium hominis/parvum. In addition, the superposition of the correlation circle with the distribution of parasites according to age groups showed that five parasitic species, including Cryptosporidium hominis/parvum, Encephalitozoon intestinalis, Hymenolepis $s p$, Dientamoeba fragilis and Trichuris trichiura were mainly associated in children aged 6 to 24 months. Enterocytozoon bieneusi was associated in children 25 to 48 months old and those older than 121 months (Fig. 3).

\section{Discussion}

This study on diarrheal disease in Gabonese children is the first to assess the prevalence of intestinal parasite infections in Franceville, Gabon. While data on adults and children already exist, children with diarrheal syndrome living in the urban environment of the city of Franceville have not previously been studied.

In this present study, we showed that $88 \%$ of the children with diarrhea were under the age of five. Our results are similar to those of a previous study performed in Franceville between 2010 and 2011 reporting a high prevalence of diarrhea in children aged one to 5 years old [20]. Similarly, in Yaoundé, Cameroon, a prevalence of $78 \%$ was also found in 2005 among children under 5 years old and living in disadvantaged environments. This study reported a prevalence of $21.5 \%$ among children of the same age group and living in residential neighborhoods [23]. Another study conducted in Ethiopia in 2017 reported a prevalence of acute diarrhea of 11.9\% among children under five in slums of Addis Ababa, which was significantly associated with inadequate sanitation and poor hygienic practices [24]. The results showing low diarrhea prevalence could be explained by recently implemented awareness programs aimed at improving sanitation and hygiene conditions in the areas studied. It is thus suggested that such programs be consistently implemented in order to curtail socioeconomic and behavioral factors that promote high prevalence of diarrhea in burdened countries.

In our study, creatinine levels are significantly higher in infected diarrheal children than in uninfected diarrheal children. Indeed, a previous study determined the proportion of morbidity attributed to S. haematobium infection and showed that, based on the results of prevalence ratios and attributable fractions, urine albumin-tocreatinine ratio (UACR) was identified as the most 


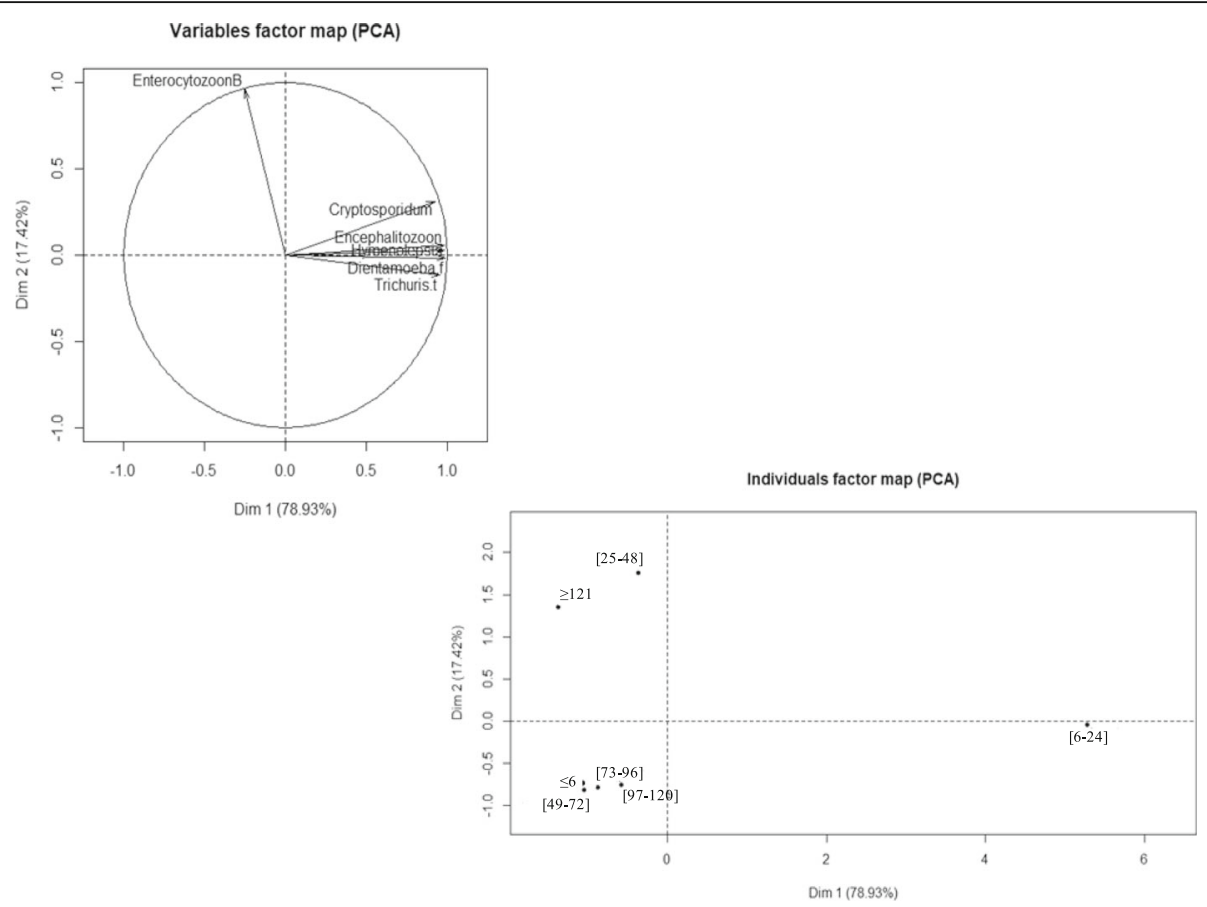

Fig. 3 Correlation between the different parasites and distribution by age group. The points on individuals factor map (PCA) represent the different clinical groups

reliable tool for detecting schistosome-related morbidity, followed by dipsticks, visual urine inspection, questionnaires and finally, clinical examination. In addition, prevalence of albuminuria determined using UACR was positively associated with the presence of microhaematuria and proteinuria detected by dipsticks. Their finding suggests that these indicators used in combination can be a better predictor of the presence of urinary tract morbidity due to $S$. haematobium infection in children than the use of a single test parameter, which would thereby facilitate effective and timely interventions [25].

A range of different pathogenic organisms can cause pediatric diarrhea in the world, especially in tropical and developing countries, including rotaviruses and adenoviruses [20,26] and bacteria such as Shigella and Eschirichia coli [27]. In the current study, we have shown that a significant percentage of pediatric diarrhea cases (61\%) are also associated with the presence of intestinal parasitic infections. Hymenolepis $s p$ was the most common pathogen accounting for $31 \%$ of cases. The second most frequent parasite in these children was Cryptosporium hominis/parvum with a prevalence of $19 \%$. Our results are consistent with other studies showing that Cryptosporium $s p$ was one of the pathogens associated with diarrhea $[28,29]$. This parasite was also linked to diarrhea in children under 5 years old and was the second leading cause of diarrhea in children after rotavirus [27].

Molecular diagnostic results showed that protozoan infections were more common compared to STH infections $\left(2 \times 10^{-6}\right)$. The highest prevalence of protozoa has also been observed in African countries including Gabon [19, 30, 31]. The low prevalence of STH infections in our study could be explained by the systematic prescription of an antihelminthic in case of digestive symptoms. Studies in Gabon have shown a reduction in the prevalence of intestinal helminths since the introduction of antihelminthics. In a clinical trial conducted in Lambarene to evaluate the efficacy of single-dose versus repeated-dose of albendazole, a significant decrease in the prevalence of intestinal parasitosis was observed [32, 33]. However, the slow development of antiparasitic immunity in children and the lack of awareness regarding the importance of personal hygiene practices may explain the high prevalence of protozoa observed in our study. Furthermore, a study conducted in Cameroon in 2011, concluded that the prevalence of protozoan infections was significantly reduced from 50.9 to $25.9 \%$ as a result of health education [34]. Other authors, however, have observed a higher prevalence of helminths compared to protozoa. The most common helminth in our study was Hymenolepis with a prevalence of $31 \%$ which is similar to other studies conducted in Burkina-Faso [35].

The global prevalence of intestinal parasitic infection was $61 \%$. Positivity was based on the results of molecular diagnostic, not on microscopic examination. However, a study conducted in different settlements of Gabon showed $61.1 \%$ of intestinal parasitic infections among school-aged children and adults by direct microscopic 
examination and the merthiolate-iodine-formaldehyde (thimerosal) concentration (MIFc) method [29]. Another study carried out in Lambaréné showed $21 \%$ of prevalence in school-age children after direct examination $[17,36]$. Parasites were not seen in our study by direct examination. Our inability to use a concentration technique may have led to the underestimation of the frequency of certain parasites. We confined ourselves to results obtained from a single parasitological examination of the stool which may have underestimated the rates of microscopic intestinal parasitism in these children.

Polyparasitism was observed in our study population with a prevalence of $19.7 \%$. In 12 polyparasitic children, $83.3 \%$ had double parasitism and $17.6 \%$ had triple parasitism. These results are consistent with those obtained in other African countries [37]. However, this rate is lower than that found in previous studies conducted in Gabon and other countries. In fact, a study conducted in different regions of Gabon showed that residing in a rural area represents a high risk factor for intestinal parasites infections [19]. Also, as seen in our study, the prevalence of IPIs observed in Gabon could be explained by the level of urbanization which remains very low in the country. Indeed, generally inadequate personal hygiene, unsafe water supplies, low levels of parental education and environmental conditions have been associated with polyparasitism.

High incidence of diarrhea were recorded between February (20\%) and May (17\%), which corresponds to the long rainy season. Other studies have also shown seasonality of rotavirus between the months of February and April [20]. High rainfall would contribute to the establishment of adequate wet conditions in which eggs and larvae could survive in the soil [38]. In terms of proportion of parasite distribution by age group, the prevalence of parasitic infections was higher among young children. Different factors such as behavioral factors and playful activities could explain this link between age and parasitic infections as described in different regions of the world $[39,40]$. No difference in intestinal parasitic infections was observed between the sexes. The prevalence of infections between boys and girls was not different either. Also, both sexes are similarly exposed to parasite-prone environments such as contaminated soil and water.

The different parasite associations highlighted in this study revealed that five parasite species were positively correlated and this link was age-dependent. In our study, Cryptosporidium hominis/parvum was associated with microsporidia with a prevalence of $25 \%$ which is higher than what was reported in other countries [41].

\section{Conclusions}

Intestinal parasitic infections with Cryptosporiduim hominis/parvum, Encephalitozoon intestinalis and Hymenolepis $s p$, were more prevalent in children in our study population. Hymenolepis sp and Cryptosporium hominis/parvum were shown to be the most frequent pediatric diarrheic infections. Moreover, the high prevalence of parasitic infections in this population of children indicates that the protozoa and helminths concerned are very common in the Franceville environment and its surroundings. Like the other main diarrhea causing agents, intestinal parasite infections are a major public health problem in Gabon. In order to better understand these parasites' distribution among pediatric diarrheic children in the region, further studies targeting sociodemographic characteristics, behavioral and hygienic practice status are required. Such studies will enable the implementation of multiple intervention strategies for children, households and their environments to reduce intestinal parasitic infections.

\section{Abbreviations \\ EDCTP: European \& Developing Countries Clinical Trials Partnership; CANT AM: Central Africa Network on Tuberculosis, HIV/AIDS and Malaria; UNEEREP: Unité d'Evolution, d'Epidémiologie et de Résistances Parasitaires}

\section{Acknowledgements}

All the authors are grateful for the participation of the children and parents from Franceville in this study. They also wish to thank the staff of the Amissa Bongo Regional Hospital of Franceville, and the Chinese-Gabonese Friendship Hospital of Franceville, for their assistance. We also would like to acknowledge the staff of the Evolution, Epidemiology and Parasite Resistance Unit at the Centre International de Recherche Médicales de Franceville (CIRMF). UNEEREP is a member of the CANTAM network funded by EDCTP. The CIRMF is supported by Total ${ }^{\oplus}$. We acknowledge Heïdi Lançon for the English revision of the manuscript.

\section{Authors' contributions}

SLOL coordinated the study, performed the statistical analysis, conducted data analysis and wrote the manuscript. GML and NKN participated in data collection and carried out the parasitological and molecular analyses. LCK carried out the molecular analysis. FM performed the statistical analysis. SKN contributed to the writing of the manuscript and JBLK conceived, designed and coordinated the study, conducted data analysis. All authors have read and approved the final manuscript.

\section{Funding}

This work was supported by Total ${ }^{\circledR}$ Gabon. The funder was not involved in the design of the study, data collection, analysis and interpretation of the data and the writing of the manuscript.

\section{Availability of data and materials}

The datasets that were used for the analysis and the preparation of this manuscript are available from the corresponding author on reasonable request.

\section{Ethics approval and consent to participate}

The study was approved by the Gabonese National Ethics Committee and the Ministry of Health (PROT N 0020/2015/SG/CNE). Stool and blood samples were collected from children after obtaining their parents' or guardians' written informed consent.

Consent for publication

Not applicable.

Competing interests

The authors declare that they have no competing interests. 


\section{Author details}

'Ecole Doctorale Régionale d'Afrique Centrale en Infectiologie Tropicale (ECODRAC), Université des Sciences et Techniques de Masuku, BP 876 Franceville, Gabon. ${ }^{2}$ Unité d'Evolution, Epidémiologie et Résistance Parasitaire (UNEEREP), Centre International de Recherches Médicales de Franceville (CIRMF), BP 769 Franceville, Gabon. ${ }^{3}$ Laboratoire d'Ecologie Vectoriel, Institut de Recherche en Ecologie Tropicale, BP 13354 Libreville, Gabon. ${ }^{4}$ Capacity for Leadership Excellence And Research (CLEAR, Inc.), Yaoundé, Cameroon. ${ }^{5}$ Département de Parasitologie-Mycologie Médecine Tropicale, Faculté de Médecine, Université des Sciences de la Santé, BP 4009 Libreville, Gabon.

\section{Received: 27 December 2019 Accepted: 4 May 2020}

\section{Published online: 15 May 2020}

\section{References}

1. Walker CLF, Rudan I, Liu L, Nair H, Theodoratou E, Bhutta ZA, et al. Global burden of childhood pneumonia and diarrhoea. Lancet. 2013;381:1405-16.

2. WHO. WHO updates fact sheet on Diarrhoeal diseases. World Health Organisation 2017. Available at: https://communitymedicine4assescom/ 2017/05/01/who-updates. Accessed 25 July 2019.

3. Pullan RL, Smith JL, Jasrasaria R, Brooker SJ. Global numbers of infection and disease burden of soil transmitted helminth infections in 2010. Parasit Vectors. 2010;7:37.

4. Boithias L, Choisy M, Souliyaseng $N$, Jourdren M, Quet F, Buisson $Y$, et al. Hydrological regime and water shortage as drivers of the seasonal incidence of diarrheal diseases in a topical montane environment. PLoS Negl Trop Dis. 2016;10:e0005195.

5. Graf J, Meierhofer R, Wegelin M, Mosler HJ. Water disinfection and hygiene behaviour in an urban slum in Kenya: impact on childhood diarrhoea and influence of beliefs. Int J Environ Health Research. 2008;18:335-55.

6. WHO. Diarrhea: Why children are still dying and what can be done. Geneva: World Health Organization 2009.

7. Stekette RW. Pregnancy, nutrition and parasitic diseases. J Nutr. 2003;133: 1661-7.

8. Oberhelman RA, Guerrero ES, Fernandez ML, Silio M, Mercado D, Comiskey $\mathrm{N}$, et al. Correlations between intestinal parasitosis, physical growth, and psychomotor development among infants and children from rura Nicaragua. Am J Trop Med Hyg. 1998;58:470-5.

9. Berkman DS, Lescano AG, Gilman RH, Lopez SL, Black MM. Effects of stunting, diarrhoeal disease, and parasitic infection during infancy on cognition in late childhood: a follow-up study. Lancet. 2002;359:564-71.

10. Nokes C, Bundy DAP. Does helminth infection affect mental processing and educational achievement? Parasitol Today. 1992;10:14-8.

11. WHO. Soil-transmitted helminth infections. Geneva: World Health Organization 2017

12. Burgess SL, Gilchrist CA, Lynn TC, Petri WA Jr. Parasitic Protozoa and Interactions with the Host Intestinal Microbiota. Infection immunity 2017; 85(8).

13. Pedersen SH, Wilkinson AL, Andreasen A, Warhurst DC. Kinunghi SM, Urassa $M$, et al. Cryptosporidium prevalence and risk factors among mothers and infants 0 to 6 months in rural and semi-rural Northwest Tanzania: a prospective cohort study. PLoS Negl Trop Dis. 2014;8:e3072.

14. CDC. Available online at: https//www.cdc.gov/parasites/giardia/infectionsources.html. 2015. Center of Disease Control and Prevention 2015. Accessed 25 July 2019

15. Osman M, El-Safadi D, Cian A, Benamrouz S, Nourrisson C, Poirier P, et al. Prevalence and risk factors for intestinal protozoan infections with Cryptosporidium, Giardia, Blastocystis and Dientamoeba among schoolchildren in Tripoli, Lebanon. PLoS Negl Trop Dis. 2016;10:e0004496.

16. Stark D, Barratt J, Chan D, Ellis JT. Dientamoeba fragilis, the neglected trichomonad of the human bowel. Clin Microbiol Rev. 2016:29:553-80.

17. Bruckner S, Agnandji ST, Berberich S, Bache E, Fernandes JF, Schweiger B, et al. Effect of Antihelminthic treatment on vaccine immunogenicity to a seasonal influenza vaccine in primary school children in Gabon: a randomized placebo-controlled trial. PLoS Negl Trop Dis. 2015;9(6): e0003768.

18. Bouyou-Akotet MK, Owono-Medang M, Moussavou-Boussougou MN, Mamfoumbi MM, Mintsa-Nguema R, Mawili-Mboumba DP, et al. Low sensitivity of the ImmunocardSTAT(R) Crypto/Giardia rapid assay test for the detection of Giardia and Cryptosporidium in fecal samples from children living in Libreville, Central Africa. J Parasitic Dis. 2016;40(4):1179-83.
19. M'Bondoukwe NP, Kendjo E, Mawili-Mboumba DP, Koumba Lengongo JV, Offouga Mbouoronde C, Nkoghe D, et al. Prevalence of and risk factors for malaria, filariasis, and intestinal parasites as single infections or co-infections in different settlements of Gabon, Central Africa. Infect Dis Poverty. 2018; $7(1): 6$.

20. Lekana-Douki SE, Kombila-Koumavor C, Nkoghe D, Drosten C, Drexler JF, Leroy EM. Molecular epidemiology of enteric viruses and genotyping of rotavirus a, adenovirus and astrovirus among children under 5 years old in Gabon. Int J Infect Dis. 2015;34:90-5.

21. Koko J, Ambara JP, Ategbo S, Gahouma D. Epidemiology of acute bacterial diarrhea in children in Libreville, Gabon. Arch Pediatrie. 2013;20(4):432-3.

22. Gotfred-Rasmussen $H$, Lund $M$, Enemark HL, Erlandsen M, Petersen E. Comparison of sensitivity and specificity of 4 methods for detection of Giardia duodenalis in feces: immunofluorescence and PCR are superior to microscopy of concentrated iodine-stained samples. Diagn Microbiol Infect Dis. 2016;84:187-90

23. Yongsi HB. Pathogenic microorganisms associated with childhood diarrhea in low-and-middle income countries: case study of Yaounde - Cameroon. Int J Environ Res Public Health. 2008:5(4):213-29.

24. Adane M, Mengistie B, Kloos H, Medhin G, Mulat W. Sanitation facilities, hygienic conditions, and prevalence of acute diarrhea among under-five children in slums of Addis Ababa, Ethiopia: baseline survey of a longitudinal study. PLoS One. 2017;12(8):e0182783.

25. Wami WM, Nausch N, Midzi N, Gwisai R, Mduluza T, Woolhouse M, Mutapi F. Identifying and evaluating field indicators of urogenital schistosomiasisrelated morbidity in preschool-aged children. PLoS Negl Trop Dis 2015(3 ):e0003649.

26. Al-thani A, Baris M, Al-Lawati N, Al-Dhahry S. Characterising the aetiology of severe acute gastroenteritis among patients visiting a hospital in Qatar using real-time polymerase chain reaction. BMC Infect Dis. 2013:13:329.

27. GBD Diarrhoeal Diseases Collaborators. Estimates of global, regional, and national morbidity, mortality, and aetiologies of diarrhoeal diseases: a systematic analysis for the Global Burden of Disease Study 2015. Lancet Infect Dis 2017:17(9):909-48.

28. Breurec S, Vanel N, Bata P, Chartier L, Farra A, Favennec L, et al. Etiology and epidemiology of diarrhea in hospitalized children from low income country: a matched case-control study in Central African Republic. PLoS Negl Trop Dis. 2016;10(1):e0004283.

29. Duong TH, Dufillot D, Koko J, Nze-Eyo'o R, Thuilliez V, Richard-Lenoble D, et al. Digestive cryptosporidiosis in young children in an urban area in Gabon. Sante. 1995;5(3):185-8.

30. M'bondoukwé PN, Mboumba-Mawili PD, Manga Mondouo F, Kombila M, Bouyou-Akotet MK. Prevalence of soil-transmitted Helminths and intestinal Protozoa in shanty towns of Libreville, Gabon. Int J Trop Dis Health. 2016; 20(3):1-9.

31. Obala A, Simiyu C, Odhiambo D, Nanyu V, Chege P, Downing R, et al. Webuye health and demographic surveillance systems baseline survey of soil-transmitted helminths and intestinal protozoa among children up to five years. J Trop Medicine. 2013

32. Adegnika AA, Zinsou JF, Issifou S, Ateba-Ngoa U, Kassa RF, Feugap EN, et al. Randomized, controlled, assessor-blind clinical trial to assess the efficacy of single- versus repeated-dose albendazole to treat Ascaris lumbricoides, Trichuris trichiura, and hookworm infection. Antimicrob Agents Chemother. 2014;58(5):2535-40.

33. Steinmann P, Utzinger J, Du ZW, Jiang JY, Chen JX, Hattendorf J, et al Efficacy of single-dose and triple-dose albendazole and mebendazole against soil-transmitted helminths and Taenia spp: a randomized controlled trial. PLoS One. 2011;6(9):e25003.

34. Fouamno Kamga HL, Shey Nsagha D, Suh Atanga MB, Longdoh Njunda A, Nguedia Assob JC, Nde Fon P, et al. The impact of health education on the prevalence of faecal-orally transmitted parasitic infections among school children in a rural community in Cameroon. Pan Afr Med J. 2011:8:38.

35. Karou SD, Sanou D, Ouermi D, Pignatelli S, Pietra V, Moret R, et al. Enteric parasites prevalence at Saint Camille medical Centre in Ouagadougou, Burkina Faso. Asian Pac J Trop Med. 2011;4(5):401-3.

36. Van den Biggelaar AH, Rodrigues LC, van Ree R, van der Zee JS, HoeksmaKruize YC, Souverijn JH, et al. Long-term treatment of intestinal helminths increases mite skin-test reactivity in Gabonese schoolchildren. J Infect Dis. 2004;189(5):892-900

37. Adoubryn KD, Kouadio-Yapo CG, Ouhon J, Aka NA, Bintto F, Assoumou A Intestinal parasites in children in Biankouma, Ivory Coast (mountaineous 
western region): efficacy and safety of praziquantel and albendazole. Med Sante Trop. 2012;22(2):170-6.

38. Brooker S, Mickael E. The potential of geographical information systems and remote sensing in the epidemiology and control of human helminth infections. Adv Parasitol. 2000;47:245-88.

39. Hurlimann E, Yapi RB, Houngbedji CA, Schmidlin T, Kouadio BA, Silue KD, et al. The epidemiology of polyparasitism and implications for morbidity in two rural communities of cote d'Ivoire. Parasites Vectors. 2014;7:81.

40. Ngui R, Ishak S, Chuen CS, Mahmud R, Lim YA. Prevalence and risk factors of intestinal parasitism in rural and remote West Malaysia. PLoS Negl Trop Dis. 2011;5(3):e974

41. Liu H, Shen Y, Yin J, Yuan Z, Jiang Y, Xu Y, et al. Prevalence and genetic characterization of Cryptosporidium, Enterocytozoon, Giardia and Cyclospora in diarrheal outpatients in China. BMC Infect Dis. 2014;14:25.

\section{Publisher's Note}

Springer Nature remains neutral with regard to jurisdictional claims in published maps and institutional affiliations.

Ready to submit your research? Choose BMC and benefit from:

- fast, convenient online submission

- thorough peer review by experienced researchers in your field

- rapid publication on acceptance

- support for research data, including large and complex data types

- gold Open Access which fosters wider collaboration and increased citations

- maximum visibility for your research: over $100 \mathrm{M}$ website views per year

At BMC, research is always in progress.

Learn more biomedcentral.com/submissions 